\title{
Avaliação do descarte de excesso de lodo secundário de FBP sobre o desempenho de reatores UASB em escala plena: estudo de caso da ETE Laboreaux - Itabira-MG
}

\section{Evaluation excess discarding of secondary sludge of PBF on the performance of UASB reactors at full scale: a case study of WTP Laboreaux - Itabira-MG}

\author{
Data de entrada: \\ $12 / 04 / 2016$ \\ - Data de aprovação: \\ 09/08/2017
}

\section{Resumo}

O presente trabalho apresenta o estudo do efeito do descarte de excesso de lodo secundário para adensamento e digestão em 4 reatores UASB da estação de tratamento de esgoto (ETE) Laboreaux de Itabira, Minas Gerais. Para tanto, avaliou-se o efeito do descarte de excesso de lodo, em função da remoção de DQQO, SST e SSed, por meio da operação dos reatores em 4 fases, sendo a fase inical com TDH médio de $18 \mathrm{~h}$ e as demais com TDH médio de 9 h. Durante o estudo, 636 dias, os reatores receberam lodo do descarte de excesso em ciclos horários de $30 \mathrm{~min}, 24 \mathrm{~h}$ por dia. Os resultados encontrados apontaram eficiências de remoção de DQO de $75 \%$, SST de $85 \%$ e SSed de $95 \%$. De modo geral, o descarte de excesso de lodo mostrou ser uma técnica vantajosa e aplicável às estações anaeróbias com unidades de pós-tratamento aeróbias (UASB+FBP), sendo os problemas operacionais até então apontados ocasionados pelo gerenciamento ineficiente de lodo nos UASB. Palavras-chave: Descarte de excesso de lodo. Tratamento de lodo. reatores UASB.

\section{Abstract}

This research studied the effect of excess discarding secondary sludge to UASB reactors for thickening and digestion in the full-scale sewage treatment plant (STP) Laboreaux in Itabira Minas Gerais. The effect of sludge excess discarding was evaluated based on COD, TSS and SSed removals through the operation of the reactors in 4 stages. The initial stage had an HRT of 18 hours and the others stages had a mean HRT of 9 hours. During the study, 636 days, the reactors received sludge from excess discharge in hourly cycles of 30 min, 24 hours per day. The results showed efficiency of removal of COD 75\%, TSS $85 \%$ and SSed $95 \%$. In general, excess sludge discarding proved to be an advantageous technique applicable to anaerobic stations with aerobic post-treatment units $(U A S B+F B P)$, with the operational problems mentioned so far caused by management of sludge in the UASB. Keywords: Sludge excess discarding. Sludge treatment. UASB reactors.

Túlio Cesar Floripes - Engenheiro Sanitarista e Ambiental pelo Centro Universitário do Leste de Minas Gerais. Mestre em Saneamento, Meio Ambiente e Recursos Hídricos pelo Departamento de Engenharia Sanitária e Ambiental da Universaidade Federal de Minas Gerais. Carlos Augusto de Lemos Chernicharo - Engenheiro Civil e Mestre em Saneamento pela Universidade Federal de Minas Gerais. Doutor em Engenharia Ambiental pela University of Newcastle Upon Tyne, Inglaterra. Pós-Doutor pela University of New South Wales, Austrália. Professor Titular do Departamento de Engenharia Sanitária e Ambiental da UFMG.

Cesar Rossas Mota Filho - Engenheiro Civil pela Universidade Federal do Ceará. Mestre em Engenharia Civil e Ambiental pela University of Nevada, Estados Unidos. Doutor em Engenharia Civil e Ambiental pela North Carolina State University, Estados Unidos. Professor Adjunto do Departamento de Engenharia Sanitária e Ambiental da UFMG.

*Endereço para correspondência: Universidade Federal de Minas Gerais, Escola de Engenharia, Departamento de Engenharia Sanitária e Ambiental. Avenida Antônio Carlos 6627, bloco 1, sala 4529. Belo Horizonte-MG, Pampulha, CEP 31270901. E-mail: tuliocesargfamsn.com. 


\section{INTRODUÇÃO}

O tratamento conjunto de águas residuárias e lodo do descarte de excesso em sistema UASB foi inicialmente discutido e proposto por Van Haandel e Letinga (1994), sendo que nos anos seguintes foram realizados diversos trabalhos sobre essa temática, todavia a grande maioria em escala piloto e de demonstração, e com lodo de descarte de excesso oriundo de outros tratamentos secundários que não o Filtro Biológico Percolador (FBP). As únicas contribuições apresentadas até o momento em estações em escala plena (UASB+FBP) foram desenvolvidas por Magalhães (2012) e Chernicharo et al. (2014).
Segundo Jenícek et al. (1999), além de minimizar a produção de lodo e de produzir um lodo mais concentrado e estabilizado, é esperado que a combinação do tratamento de água residuária e lodo de excesso atenda aos requisitos de remoção de material orgânico típico do tratamento de águas residuárias (em torno de 60 a 80\%), e da digestão do lodo no que se refere a remoção de sólidos voláteis (40 a 50\%).

A Tabela 1 apresenta um resumo dos trabalhos sobre recirculação de lodo e das eficiências e concentrações efluentes médias encontradas até o momento na literatura, considerando apenas os efluentes do UASB.

Tabela 1 - Resumo dos trabalhos sobre descarte de excesso de lodo para adensamento e digestão em reatores UASB tratando esgoto doméstico

\begin{tabular}{|c|c|c|c|c|c|}
\hline \multirow{2}{*}{ Fonte } & \multirow{2}{*}{ Origem do lodo Secundário } & \multicolumn{2}{|c|}{ Resultados Efluente UASB } & \multicolumn{2}{|c|}{ Eficiência de Remoção } \\
\hline & & DQO (mg.L-1) & SST (mg. $\left.\mathrm{L}^{-1}\right)$ & DQQO (\%) & SST (\%) \\
\hline SOUSA (1996) & Reatores Sequencial de Batelada & 58,1 & 38 & 86 & 85 \\
\hline ORTEGA et al (1996) & Lodo Ativado & - & - & 78 & - \\
\hline BOF et al (1999) & Biofiltro Aerado Submerso & 136 & 41 & 79 & 76 \\
\hline FREIRE, von SPERLING e CHERNICHARO (1999) & Lodo Ativado & 114 & 30 & 84 & 85 \\
\hline COURA e VAN HAANDEL (1999) & Lodo Ativado & 315 & 90 & 60 & 73 \\
\hline GONÇALVES et al (1999) & Lodo Ativado & 101 & 34 & 91 & 94 \\
\hline VERONEZ (2001) & Biofiltro & 95 & 52 & - & - \\
\hline AISSE et al (2001) & Biofiltro Aerado Submerso & 162 & 78 & 57 & 50 \\
\hline WANKE et al (2002) & Biofiltro Aerado Submerso & 66 & 15 & 88 & 94 \\
\hline GONÇALVES et al (2002) & Biofiltro Aerado Submerso & 186 & 77 & 64 & 63 \\
\hline PONTES (2003) & Filtro Biológico Percolador & 104 & 66 & 75 & - \\
\hline COSENTINO et al (2005) & Lodo Ativado & 167 & - & 76 & - \\
\hline CASEIRO, PIVELI e SOBRINHO (2006) & Lodo Ativado & 239 & 72 & 67 & 42 \\
\hline PONTES e CHERNICHARO (2009) & Filtro Biológico Percolador & 164 & 42 & 65 & 81 \\
\hline SILVA FILHO e VAN HAANDEL (2014) & Lodo Ativado & 170 & 275 & 60 & - \\
\hline
\end{tabular}

Fonte - Adaptado de Caseiro, Piveli e Além Sobrinho (2006).

Nota-se pela leitura dos textos acima que é consenso entre os autores o potencial da aplicação da técnica do descarte de excesso de lodo, devido à não observação de impactos negativos aos sistemas de tratamento global. Alguns autores apresentam, inclusive, pontos positivos, como o aumento da produção de metano e a redução da produção de lodo, bom desempenho na digestão do lodo aeróbio (podendo comparar o sistema ao fluxograma tradicional de lodos ativados) e aumento na atividade metanogênica específica. Entretanto, ressalta-se que todos esses trabalhos foram realizados em escala piloto ou escala de demonstração, sob condições controladas, o que nem sempre acontece em estações operando em escala plena.

No que se refere aos trabalhos realizados com os sistemas UASB/FBP, Pontes (2003) e Pontes e Chernicharo (2009) inferiram que a combinação 
do processo de tratamento anaeróbio de águas residuárias com a digestão da biomassa de descarte de excesso pode conferir grande viabilidade econômica ao sistema de tratamento.

Entretanto, de acordo com Kassab et al. (2010), o descarte de excesso de biomassa tem sido apontado como causa de perdas de sólidos no efluente de reatores UASB operando em escala plena no Brasil. Segundo Pontes (2003), isso possivelmente se deve à presença de partículas com menores dimensões em pontos mais elevados do reator UASB, resultando na necessidade de descartes mais frequentes de biomassa nos reatores.

A degradação do efluente do UASB pode ser relacionada com o gerenciamento ineficiente da massa de lodo interna, uma vez que grandes acúmulos de lodo dentro do reator ocasionam grandes perdas de sólidos no efluente tratado. Resultando assim em baixa retenção de sólidos pelo FBP, o que implica em um lodo de excesso no DS instável e com altas concentrações (variação de $3 \%$ a $4 \%$ ), de características muito próximas às do lodo do UASB.

Em trabalho mais recente realizado na ETE Onça, Belo Horizonte, Chernicharo et al. (2014) avaliaram, comparativamente, durante 12 meses, 4 dos 24 reatores (volume unitário de cada reator igual a $2.285 \mathrm{~m}^{3}$ e TDH médio de operação igual a 7 horas) - em que apenas 2 dos 4 reatores recebiam descarte de lodo de excesso, sendo observado nesses reatores excessivo aumento de perda de sólidos. Todavia, os autores atribuíram o aumento da perda de sólidos nos reatores a um somatório de fatores, notadamente o lodo de excesso com concentração bastante elevada ( $3 \%$ a $4 \%$ de sólidos) e à incapacidade do sistema de desidratação em processar todo o lodo produzido nos UASB (apenas uma das duas centrífugas necessárias esteve em funcionamento durante a maior parte da pesquisa), o que ocasionou aumento no tempo de retenção do lodo nos reatores UASB e consequente elevação da manta de lodo.
Sobre o efeito do lodo de excesso dos decantadores secundários (DS) sobre a performance dos reatores UASB, Chernicharo et al. (2014) relatam que, comparativamente, os dois reatores que receberam lodo de excesso apresentaram concentrações bem mais elevadas de SST, SSed e $\mathrm{DQO}_{\text {total }}$ que os dois reatores que não receberam lodo de excesso. Entretanto, nos períodos 4 e 5, quando foi possível aumentar a frequência de descarte de lodo dos reatores que operavam com excesso de lodo, observou-se uma significativa melhora na qualidade dos efluentes desses reatores, particularmente para o parâmetro DQQO, cujas concentrações medianas foram 165 e 174 $\mathrm{mg} . \mathrm{L}^{-1}$ para os reatores sem recebimento de lodo de excesso, e 200 e $162 \mathrm{mg} \cdot \mathrm{L}^{-1}$ para os reatores com recebimento de excesso de lodo.

Por outro lado, a elevação das concentrações de SST, SSed e DQO $\mathrm{O}_{\text {total }}$ nos efluentes dos reatores com recebimento de lodo de excesso aparentemente não afetou as concentrações de $\mathrm{DQO}_{\text {filtrada }}$, que se mantiveram muito próximas nos 4 reatores UASB da pesquisa, em todos os períodos operacionais, $O$ que é uma indicação de que o descarte do lodo de excesso não afetou a atividade microbiológica nos reatores (CHERNICHARO et al., 2014).

Embasado nos problemas anteriormente descritos e discutidos na literatura, o presente estudo teve como objetivo avaliar o efeito do descarte de excesso de lodo secundário sobre o desempenho dos reatores UASB na ETE Laboureaux em Itabira-MG, buscando analisar o comportamento dos reatores UASB quanto aos parâmetros $\mathrm{DQO}_{\text {total' }}$ Sólidos Totais e Sólidos Sedimentáveis.

\section{MATERIAL E MÉTODOS}

A execução desse estudo foi realizada na Estação de Tratamento de Esgoto Laboreaux, localizada na cidade de Itabira-MG, sendo a ETE constituída de unidades de tratamento preliminares, reatores anaeróbios de fluxo ascendente e manta de 
lodo (UASB), filtros biológicos percoladores (FBP) e decantadores secundários (DS). A realização do estudo incluiu a operação assistida e o monitoramento da estação, sendo o fluxograma de tratamento dimensionado para operação com descarga do excesso de lodo para adensamento e digestão em reatores UASB. A Tabela 2 apresenta as características das principais unidades de tratamento. Para o desenvolvimento da pesquisa, foram selecionados quatro reatores (2 blocos), denominados de R1, R2, R3 e R4.

Tabela 2 - Características principais da ETE Laboreaux

\begin{tabular}{|c|c|c|c|}
\hline Características & $\begin{array}{c}\text { Reatores } \\
\text { UASB }\end{array}$ & $\begin{array}{c}\text { Filtros } \\
\text { biológicos } \\
\text { percoladores } \\
\text { (FBP) }\end{array}$ & $\begin{array}{c}\text { Decantadores } \\
\text { secundários } \\
\text { (DS) }\end{array}$ \\
\hline População (hab.) & & 70.000 & \\
\hline Vazão (L.s $\left.{ }^{-1}\right)$ & & 170 & 2 \\
\hline Número de unidades & 8 (4 blocos) & 2 & Circular \\
\hline Tipo & Retangular & Circular & D $=20,0$ \\
\hline Dimensões $(m)$ & $21,7 \times 6,2$ & D $=22,5$ & 314,0 \\
\hline Área $\left(m^{2}\right)$ & 134,5 & 397,6 & 3,0 \\
\hline Profundidade útil $(m)$ & 4,5 & 2,5 & 942 \\
\hline Volume útil $\left(m^{3}\right)$ & 605,25 & - & \\
\hline
\end{tabular}

A partir da Fase 1, fez-se necessária a adequação do TDH dos quatro reatores selecionados para $9 \mathrm{~h}$ (sendo esse o TDH médio de projeto). Para tanto, realizou-se a adequação das vazões por meio da alteração da altura das comportas da caixa distribuidora de vazão (CDV1) utilizando a equação do vertedor retangular. As comportas de alimentação dos reatores 5 a 8 (blocos 3 e 4) foram içadas até a altura de 5,5 cm e as comportas de alimentação dos reatores 1 a 4 (blocos 1 e 2) mantidas a nível da soleira. A vazão nos vertedores foi aferida pelo uso de régua com base na vazão média afluente de 40 L.s. ${ }^{-1}$ para os blocos 1 e 2, e 20 L.s ${ }^{-1}$ para os blocos 3 e 4 considerando uma vazão média de 100 L.s $^{-1}$ (ou seja, os reatores 1 a 4 operaram com $80 \%$ da vazão total). A vazão total da estação foi medida automaticamente no canal parshall ao longo do dia por sensor ultrassônico.

O descarte de lodo de excesso para os reatores UASB foi realizado por meio da estação elevatória de recirculção de lodo (ERL) equipada com duas bombas centrífugas de $5 \mathrm{cv}$ de potência. $\mathrm{O}$ sistema de automação da ETE possibilitava a operação das bombas em ciclos horários (30 minutos por decantador - 26 minutos de bombeamento e quatro minutos de descanso) durante 24 horas. Durante a pesquisa, em cada ciclo de operação da ERL, por decantador, foi bombeado um volume de lodo secundário equivalente a $1,26 \mathrm{~m}^{3}$, por batelada (volume compreendido entre os níveis 0,70 e 1,20 m do poço de sucção), totalizando $2,52 \mathrm{~m}^{3} \cdot \mathrm{h}^{-1}\left(0,70 \mathrm{~L} \cdot \mathrm{s}^{-1}\right)$. A recirculação de lodo de excesso era acionada quando o nível de lodo no poço de sucção chegava a 1,20 $\mathrm{m}$, sendo desligado quando o nível atingia $0,70 \mathrm{~m}$. Neste momento, a válvula de descarte do sistema de decantação (DS1 ou DS2) era acionada para enchimento do poço de lodo e reinício da recirculação de lodo para a elevatória de esgoto bruto 2 .

O monitoramento da ETE foi realizado por análises na fase líquida (2 vezes por semana) dos parâmetros, Demanda Química de Oxigênio (DQQ), Sólidos Suspensos Totais (SST) e Sólidos Sedimentáveis (SSed), nos afluentes e efluentes de cada unidade de tratamento. Para a fase sólida, o monitoramento foi realizado por meio da análise dos perfis de sólidos -- Sólidos Totais (ST) e Sólidos Totais Voláteis (STV) _-nos reatores anaeróbios. Todos os parâmetros foram analisados segundo o Standard Methods for the Examination of Water and Wastewater, com análise de DQO pelo método 5220D (APHA, 2005).

A pesquisa foi desenvolvida em seis fases, como pode ser observado na Tabela 3, onde apresentam-se o resumo das fases estudadas e a sistemática de descarte de lodo. 
Tabela 3 - Caracterização das fases operacionais da pesquisa

\begin{tabular}{|c|c|c|c|}
\hline Fase Operacional & Duração (dias) & Descrição & Sistemática de descarte de lodo \\
\hline 0 & 174 & $\begin{array}{l}\text { Fase de monitoramento e estudo do comportamento } \\
\text { dos reatores operando em subcarga, com TDH médio } \\
\text { de } 17 \text { h. Essa era a condição usual de operação da } \\
\text { ETE, tendo em vista que as vazões afluentes à mesma } \\
\text { ainda estavam bem abaixo da vazão de projeto. }\end{array}$ & $\begin{array}{l}\text { Descarte de } 10 \mathrm{~m}^{3} \text { de lodo por reator, por dia. } \\
\text { Seguindo rotina de rodízio, conforme o manual de } \\
\text { projeto da ETE. }\end{array}$ \\
\hline 1 & 146 & $\begin{array}{l}\text { A partir da Fase } 1 \text { (até a Fase 4), ajustou-se a vazão } \\
\text { de alimentação em } 4 \text { dos } 8 \text { reatores da ETE, para } \\
\text { que os mesmos pudessem operar com TDH próximo } \\
\text { ao de projeto ( } 9 \text { horas), de modo a conferir maior } \\
\text { representatividade aos resultados da pesquisa. } \\
\text { Dessa forma, os reatores UASB } 1,2,3 \text {, e } 4 \text { passaram a } \\
\text { receber, igualitariamente, quase toda a vazão afluente } \\
\text { à ETE, com a vazão residual sendo encaminhada para } \\
\text { os demais reatores }(5,6,7 \text { e } 8) \text {. }\end{array}$ & $\begin{array}{l}\text { Descarte de } 10 \mathrm{~m}^{3} \text { de lodo por reator, por dia. } \\
\text { Seguindo rotina de rodízio, conforme o manual de } \\
\text { projeto da ETE. }\end{array}$ \\
\hline 2 & 45 & $\begin{array}{l}\text { Implementação de rotina de interrupção da } \\
\text { alimentação dos reatores UASB } 1 \text { e } 2 \text { por uma hora, de } \\
\text { modo a conseguir maior adensamento do lodo antes } \\
\text { da operação de descarte, o que poderia resultar em } \\
\text { maiores descartes de lodo para um mesmo volume } \\
\text { processado pelo filtro prensa. O descarte de lodo } \\
\text { dos reatores } 3 \text { e } 4 \text { foi mantido como antes, sem a } \\
\text { interrupção de alimentação desses reatores. }\end{array}$ & $\begin{array}{l}\text { Descarte de } 10 \mathrm{~m}^{3} \text { de lodo por reator, por dia. Com } \\
\text { paralisação dos reatores } 1 \text { e } 2 \text { por uma hora, para } \\
\text { posterior descarte. E descarte normal dos reatores } \\
3 \text { e } 4 \text {. Os demais reatores seguiram o procedimento } \\
\text { operacional padrão. }\end{array}$ \\
\hline 3 & 87 & $\begin{array}{l}\text { Visando reduzir a quantidade de lodo de descarte } \\
\text { e reduzir a perda de sólidos nos reatores, foi então } \\
\text { implementada nova rotina para descarte de lodo dos } \\
\text { reatores, com descartes maiores nos reatores } 1 \text { e } 2 \text {, e } \\
\text { menores nos reatores } 3 \text { e } 4 \text {. Para esta fase, reviu-se } \\
\text { o coeficiente de produção de lodo nos reatores, } \\
\text { considerando o acréscimo de carga orgânica oriunda } \\
\text { do lodo de descarte. }\end{array}$ & $\begin{array}{l}\text { Descarte de } 20 \mathrm{~m}^{3} \text { de lodo dos reatores } 1 \text { e } 2 \text {, e de } \\
10 \mathrm{~m}^{3} \text { dos reatores } 3 \text { e } 4 \text { por dia. Os demais reatores } \\
\text { seguiram o procedimento operacional padrão. }\end{array}$ \\
\hline $4 \mathrm{~A}$ & 56 & $\begin{array}{l}\text { Retirada de passivo de lodo até que a concentração } \\
\text { à altura de } 2,0 \text { m fosse reduzida a valores próximos } \\
\text { a 0,5\%, de modo a garantir que não haveria lodo no } \\
\text { interior do compartimento de decantação dos UASB. } \\
\text { Foi também removido o passivo de lodo dos DS por } \\
\text { meio da recirculação contínua de lodo por } 15 \text { dias. } \\
\text { Durante essa etapa da pesquisa fez-se necessário } \\
\text { o aumento das bateladas do filtro prensa de } 6 \text { para } \\
8 \text { por dia, fazendo assim com que a capacidade de } \\
\text { desidratação por dia da ETE de } 60 \mathrm{~m}^{3} \text { fosse utilizada. }\end{array}$ & $\begin{array}{l}\text { Descarte de } 30 \mathrm{~m}^{3} \text { de lodo por reator, por dia (um } \\
\text { reator por semana, de } 2 \text { a a 6a feira) e descarte de } 10 \\
\mathrm{~m}^{3} \text { por dia dos demais reatores. Sendo o descarte } \\
\text { realizado apenas nos reatores da pesquisa. Ex.: } 1^{\mathrm{a}} \\
\text { Semana: descarte de } 30 \mathrm{~m}^{3} \mathrm{R} 1 \text { e descarte de } 10 \mathrm{~m}^{3} \mathrm{R} 2 \text {, } \\
\mathrm{R} 3 \text { e R4. } 2^{\mathrm{a}} \text { Semana: descarte de } 30 \mathrm{~m}^{3} \mathrm{R} 2 \text { e descarte } \\
\text { de } 10 \mathrm{~m}^{3} \mathrm{R} 1, \mathrm{R} 3 \text { e R4. }\end{array}$ \\
\hline $4 \mathrm{~B}$ & 117 & $\begin{array}{l}\text { Monitoramento e manutenção do perfil de lodo nos } \\
\text { reatores UASB por meio de descarte de } 8 \mathrm{~m}^{3} \text { de lodo } \\
\text { por reator, por dia, considerando a concentração do } \\
\text { lodo a } 1 \% \text { na altura descarte }(2,0 \mathrm{~m}) \text {. }\end{array}$ & $\begin{array}{l}\text { Descarte de } 8 \mathrm{~m}^{3} \text { de lodo dos reatores } 1 \text { a } 4 \text { por dia. } \\
\text { E descarte de } 10 \mathrm{~m}^{3} \text { por dia dos demais reatores, } \\
\text { visando à retirada do passivo de lodo e problemas } \\
\text { futuros de perda de sólidos. }\end{array}$ \\
\hline
\end{tabular}

\section{RESULTADOS E DISCUSSÃO}

\subsection{Condições Operacionais}

A Figura 1 apresenta as vazões médias e os corres-
pondentes tempos de detenção hidráulica (TDH) ao longo dos 645 dias de monitoramento dos quatros

reatores da ETE Laboreaux. Na Figura 2, são mostradas as vazões e os TDH (valores médios) dos reatores UASB ao longo das 24 horas do dia, para as fases 0 a 4 . 


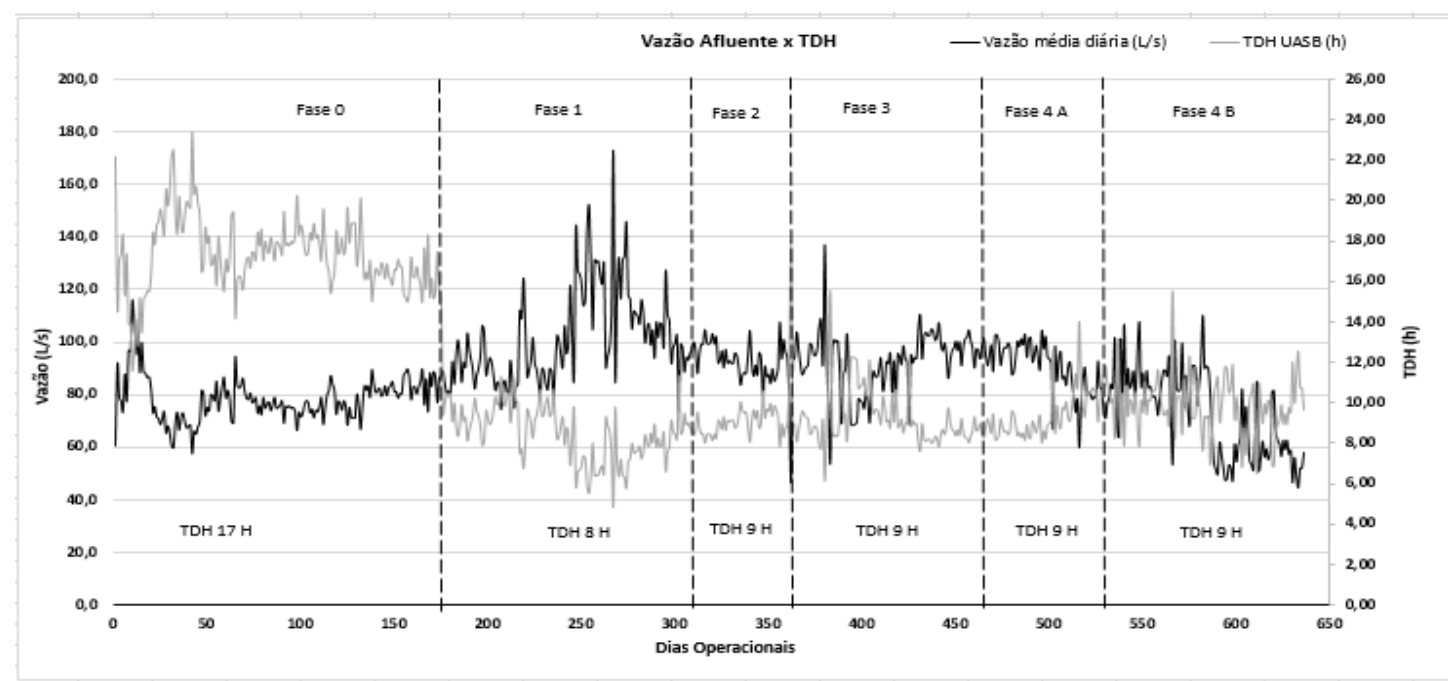

Figura 1 - Hidrograma de Vazão versus Tempo de Detenção Hidráulica (TDH)

A análise das Figuras 1 e 2 permite os seguintes comentários:

- A adequação do TDH médio da ETE Laboreaux, de $18 \mathrm{~h}$ para $9 \mathrm{~h}$, foi essencial para o ideal monitoramento da estação, uma vez que o TDH ajustado se aproxima do que é usualmente definido em projeto de reatores UASB, contribuindo assim para que outras estações possam reproduzir o estudo desenvolvido.

- As vazões médias afluentes (Figura 1) aos quatro reatores da ETE Laboreaux, na Fase 0, mantive-

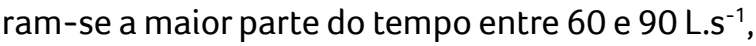
apresentando aproximadamente $50 \%$ de vazão inferior ao valor de projeto (170 L.s $\left.{ }^{-1}\right)$. Nas fases 1 a 4, os valores de vazão se mantiveram entre $80 \mathrm{e}$ 105 L.s $^{-1}$, com um pico de 172 L.s $^{-1}$ verificado no dia 26/12/2013, superior à vazão de projeto, ocasionado pela entrada de águas pluviais no sistema de esgotamento devido ao rompimento do interceptor de esgoto próximo a chegada da ETE.

- Os TDHs médios dos quatro reatores (Figura 1) se mantiveram na fase 0 , entre 12 e 19 horas, apresentando valores inferiores à média de 18 horas. Após adequação do TDH nos reatores, fases 1 a 4 , nota-se que o TDH se manteve entre 8 e 10 horas, apresentando valores variando entre 6 e 8 horas entre os dias 255 e 297 em função do aumento da vazão afluente devido ao período de chuva. 0 comportamento da vazão e do TDH nos reatores, em cada fase, pode ser melhor visualizado na Figura 2, onde se apresentam as médias diárias (24 horas) de vazão e TDH. 


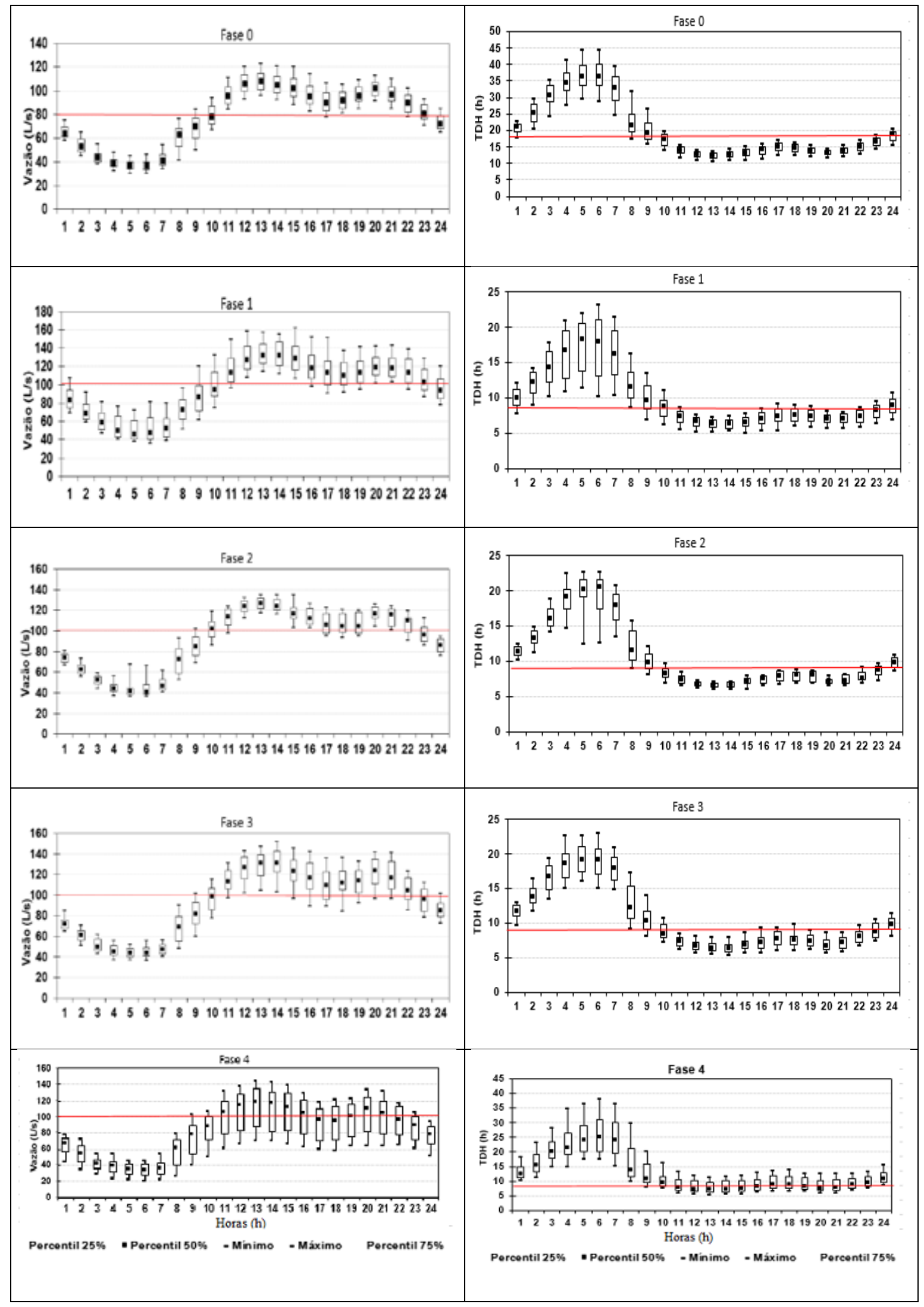

Figura 2 - Vazões médias diárias e TDH médios diários 
- Em relação à Figura 2, os perfis de variação das vazões afluentes à ETE Laboreaux mostraram que os reatores UASB durante as fases 0 a 3 operaram a maior parte do dia (10:00 às 23:00 horas -13 horas) com TDH abaixo do médio. $O$ melhor ajuste de TDH foi observado na fase 4 , onde observa-se TDH médio diário (no período de 10:00 às 23:00 horas) próximo de 9 horas (TDH de projeto).

- A variação do TDH, apresentado nas fases 2 a 3 , pode ser relacionada a sinistros operacionais observados ao longo da pesquisa, como o rompimento do interceptor, paralisação de um reator devido ao rompimento da lona do separador trifásico, etc.

A Tabela 4 apresenta a média dos principais parâmetros operacionais dos reatores UASB e dos decantadores secundários para as cinco fases da pesquisa. A análise da Tabela permite os seguintes comentários:

- Os parâmetros médios, mostrados na Tabela 4, indicam que não existiu sobrecarga hidráulica nas unidades de tratamento estudadas, uma vez que as vazões mensuradas foram inferiores à de projeto.
- O TDH mais elevado, na fase 0 , implicou em menores valores de velocidade superficial, o que pode ter propiciado alta sedimentação de sólidos nos reatores.

- Em relação às cargas orgânicas (esgoto mais lodo de excesso), nota-se que na fase 0 os valores de carga orgânica volumétrica afluente foram aproximadamente $50 \%$ inferiores aos valores notados nas demais fases. $O$ aumento da carga observado nas fases 1 a 3 se deu provavelmente via recirculação de lodo de excesso com alta concentração (3 a 4 \%) dos DS. A concentração incomum do lodo, observada nos DS, para fases 1 a 3, ocorreu em função da alta perda de sólidos dos UASB no momento do aumento da vazão nos reatores, tendo ainda como causa a falta de produtos químicos necessários ao condicionamento do lodo (como sulfato ferroso), a quebra de placas do filtro prensa e a baixa quantidade de leitos de secagem (apenas 4), o que resultou em acúmulo de lodo nos decantadores e reatores. Cabe ressaltar que os FBP não foram capazes de estabilizar os sólidos carreados dos UASB, cabendo assim aos DS retenção de grande parte desse material.

Tabela 4 - Médias dos principais parâmetros operacionais das unidades de tratamento

\begin{tabular}{|c|c|c|c|c|c|c|c|}
\hline \multirow[b]{2}{*}{ Fase } & \multicolumn{2}{|c|}{ Parâmetros da ETE } & \multicolumn{3}{|c|}{ Parâmetros dos reatores UASB } & \multicolumn{2}{|c|}{ Parâmetros dos DS } \\
\hline & $\stackrel{\mathbf{Q}}{\left(L . s^{-1}\right)}$ & $\begin{array}{c}\text { COV } \\
\left(\mathrm{kgDQO} \cdot \mathrm{m}^{-3} \cdot \mathrm{d}^{-1}\right)\end{array}$ & $\begin{array}{c}\text { TDH } \\
\text { (h) }\end{array}$ & $\begin{array}{c}\text { Velocidade } \\
\text { superficial } \\
\left(\mathrm{m} \cdot \mathrm{h}^{-1}\right)\end{array}$ & $\begin{array}{c}\text { COV }^{*} \\
\left(\mathrm{kgDQO} \cdot \mathrm{m}^{-3} \cdot \mathrm{d}^{-1}\right)\end{array}$ & $\begin{array}{c}\text { TAS } \\
\left(m^{3} \cdot m^{-2} \cdot d^{-1}\right)\end{array}$ & $\begin{array}{c}\text { TDH } \\
\text { (h) }\end{array}$ \\
\hline 0 & 78,5 & 0,77 & 17,3 & 0,26 & 0,77 & 10,8 & 13,3 \\
\hline 1 & 101,2 & 1,04 & 8,9 & 0,54 & 1,8 & 22,3 & 6,5 \\
\hline 2 & 91,3 & 1,12 & 9,3 & 0,49 & 1,8 & 20,1 & 7,2 \\
\hline 3 & 92,6 & 1,08 & 9,2 & 0,50 & 1,6 & 20,4 & 7,1 \\
\hline 4 & 98 & 1,44 & 9,4 & 0,52 & 2,2 & 21,6 & 6,7 \\
\hline
\end{tabular}

* No período entre as fases 1 a 4 os quatro reatores da pesquisa operaram com $80 \%$ da vazão afluente

Q: vazão, COV: Carga Orgânica Volumétrica, TDH: Tempo de Detenção Hidráulica, TAS: Taxa de Aplicação Superficial 


\subsection{Efeito do Descarte de Lodo de Excesso sobre o Desempenho dos Reatores UASB}

O efeito da adequação do TDH e descarte de lodo de excesso sobre os reatores pode ser avaliado de forma geral pelas Figuras 3 a 5, que apresentam os gráficos de série histórica para os pontos CDV 1 e efluente apenas dos UASB (R1 a R4) e boxplot dos pontos CDV 1 (caixa de distribuição de esgoto, onde o esgoto bruto afluente é misturado ao lodo de excesso vindo dos DS), CDV 2 (afluente dos 4 reatores) e $E F$ (efluente final da ETE) para os parâmetros DQO $_{\text {total' }}$ SST e SSed. A análise das Figuras 3 a 5 permite os seguintes comentários:

\section{Fase 0}

- O valor médio afluente aos reatores anaeróbios foi de $550 \mathrm{mg} \cdot \mathrm{L}^{-1}$ de DQQO, resultando em uma carga orgânica volumétrica média de $0,77 \mathrm{kgD}$ Q $0 . \mathrm{m}^{-3} \cdot \mathrm{d}^{-1}$ afluente à estação. Para esse período da pesquisa, nota-se que a concentração de DQO efluente dos reatores variou de 147 a $168 \mathrm{mg}^{-L^{-1}}$, apresentando uma eficiência média de remoção da ordem de $73 \%$. Notam-se também, concentrações efluentes baixas para os parâmetros SST e SSed, resultando em elevadas eficiências de remoção, de 84 e $88 \%$, respectivamente.

- Os valores de eficiência de remoção observados (Figuras 3 a 5) se aproximam dos valores comumente observados em estações que operam sem descarte de lodo de excesso, o que permite deduzir que os reatores não sofreram impactos negativos nesse período, operando de forma estável. Sobre os dados apresentados, cabe ressaltar que apesar dos elevados percentuais de remoção observados na fase 0 (TDH de 18 h) existe uma grande inviabilização de dimensionamento de reatores com o tempo de detenção hidráulico adotado, uma vez que demandaria áreas maiores e maior quantidade de reatores.

\section{Fase 1}

- A diminuição do TDH e consequente aumento da vazão nos reatores implicou em instantânea perda de eficiência, com concentrações efluentes próximas às afluentes, devido ao revolvimento de sólidos que se encontravam sedimentados. Após uma hora de adequação de TDH, os valores efluentes de SSed observados foram da ordem de $60 \mathrm{~mL} . \mathrm{L}^{-1}$, nos quatro reatores. Essas observações também são mencionadas na literatura por Silva e van Haandel (2014), que observaram em trabalho realizado com reatores UASB a deterioração da qualidade do efluente anaeróbio decorrente do descarte de lodo aeróbio de excesso, notadamente sobre a concentração de sólidos sedimentáveis, que aumentou muito quando a carga de lodo aeróbio foi aumentada.

- O acréscimo da vazão em aproximadamente $100 \%$, em cada um dos 4 reatores, resultou na elevação da carga orgânica volumétrica média para $1,8 \mathrm{kgDQO} . \mathrm{m}^{-3} \cdot \mathrm{d}^{-1}$ (aumento de $135 \%$ em relação a fase 0 ), ocasionando, consequentemente, o aumento da produção de lodo.

- A observação da Figura 3b aponta para desempenho insatisfatório dos reatores, produzindo efluente com concentrações inaceitáveis, com baixa eficiência (35\%) de remoção de DQO, e concentração efluente média de $355 \mathrm{mg} \cdot \mathrm{L}^{-1}$.

- A concentração efluente de SST nos reatores variou de 204 a $224 \mathrm{mg}^{\mathrm{L}} \mathrm{L}^{-1}$, representando apenas $38 \%$ de remoção de sólidos (Figura 3 b).

- A concentração efluente média de sólidos sedimentáveis foi de $3 \mathrm{~mL} . \mathrm{L}^{-1}$ e a eficiência de remoção, de 50 \%. Nota-se na Figura 5 a que os valores efluentes estiveram sempre próximos aos valores afluentes dos UASB, o que demonstra a baixa eficiência de remoção do sistema.

- De modo geral, os valores relatados são preocupantes do ponto de vista operacional, uma vez que grande parte das elevadas perdas de biomassa dos reatores UASB não foi estabilizada nos FBP, sendo a biomassa retida nos decantadores, onde dada a elevada carga de sólidos, parte destes não sedimentou e, consequentemente, foi lançada com o efluente final. 

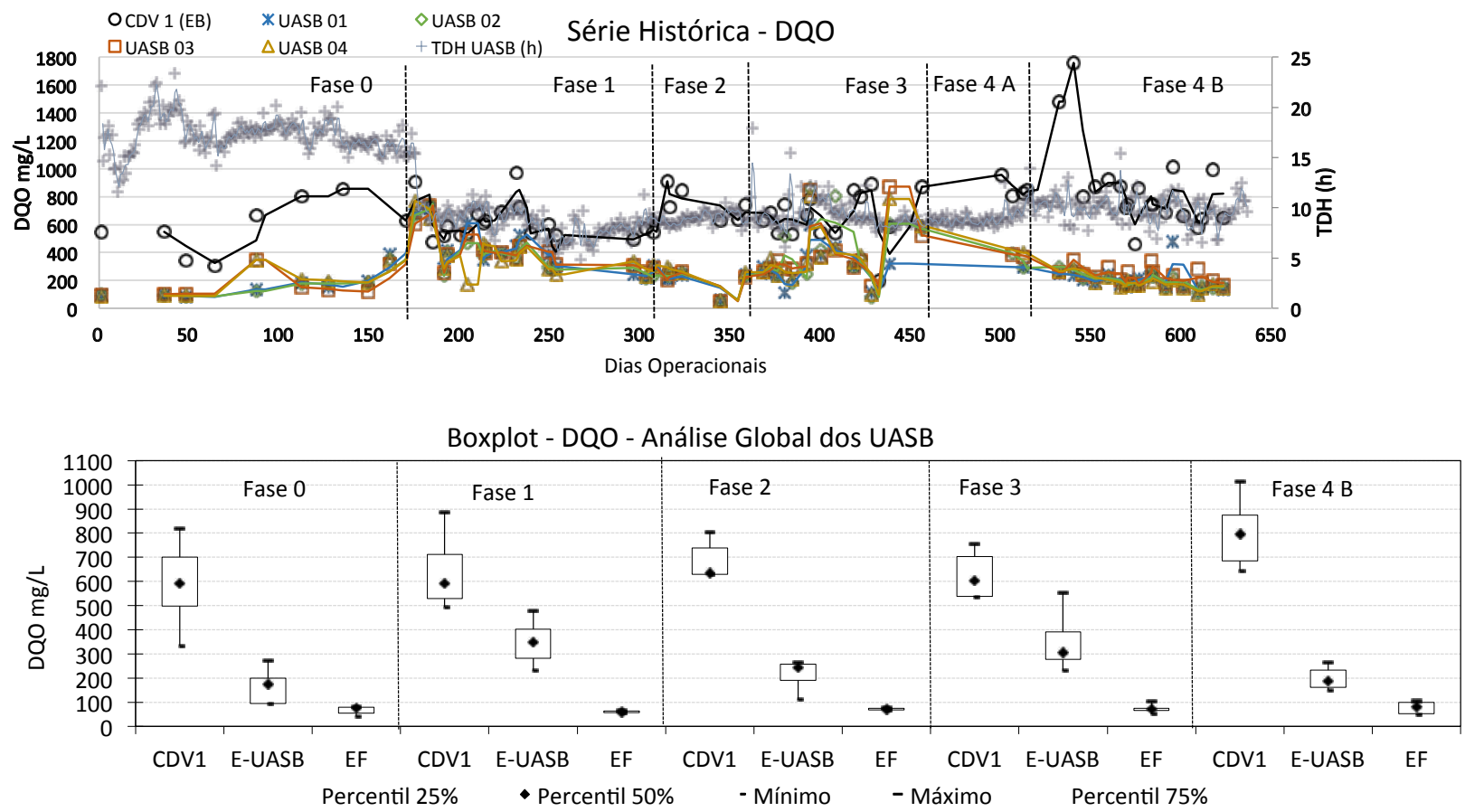

Figura 3 - a) Série Histórica (Afluente e Efluentes dos Reatores) e b) Boxplot análise Global para DQQO (Afluente e Efluente da Estação)

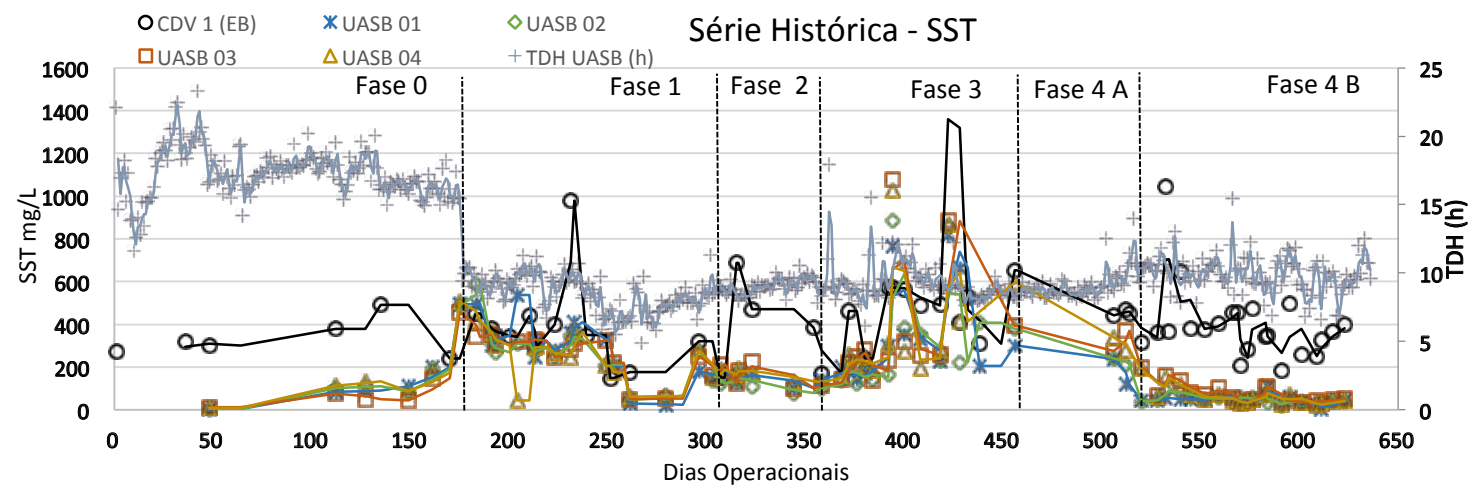

Boxplot - SST - Análise Global

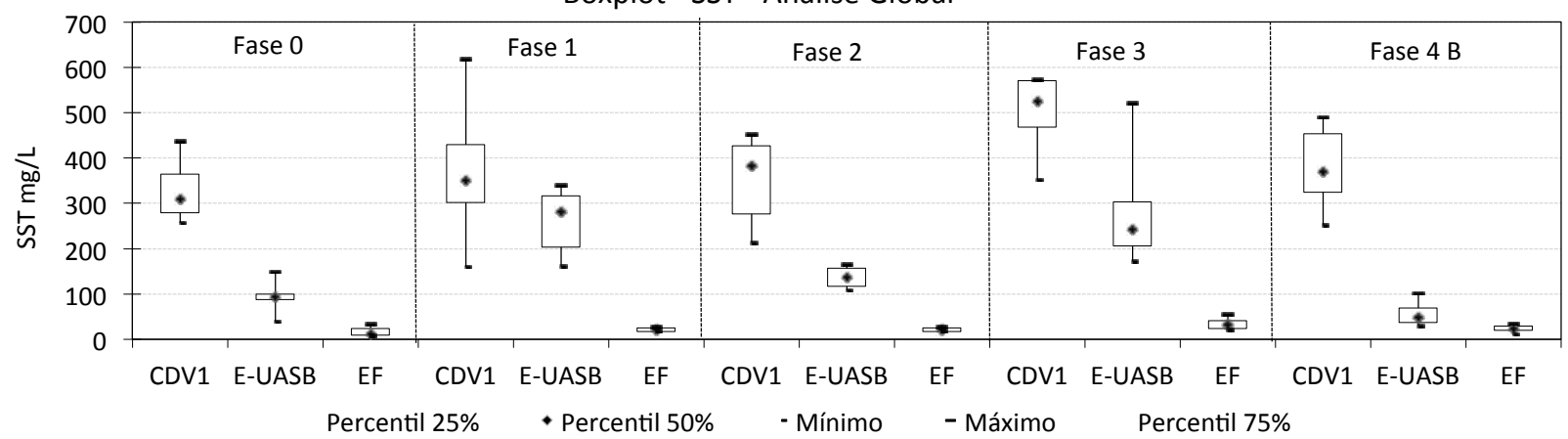

Figura 4 - a) Série Histórica (Afluente e Efluentes dos Reatores) e b) Boxplot análise Global para SST (Afluente e Efluente da Estação) 


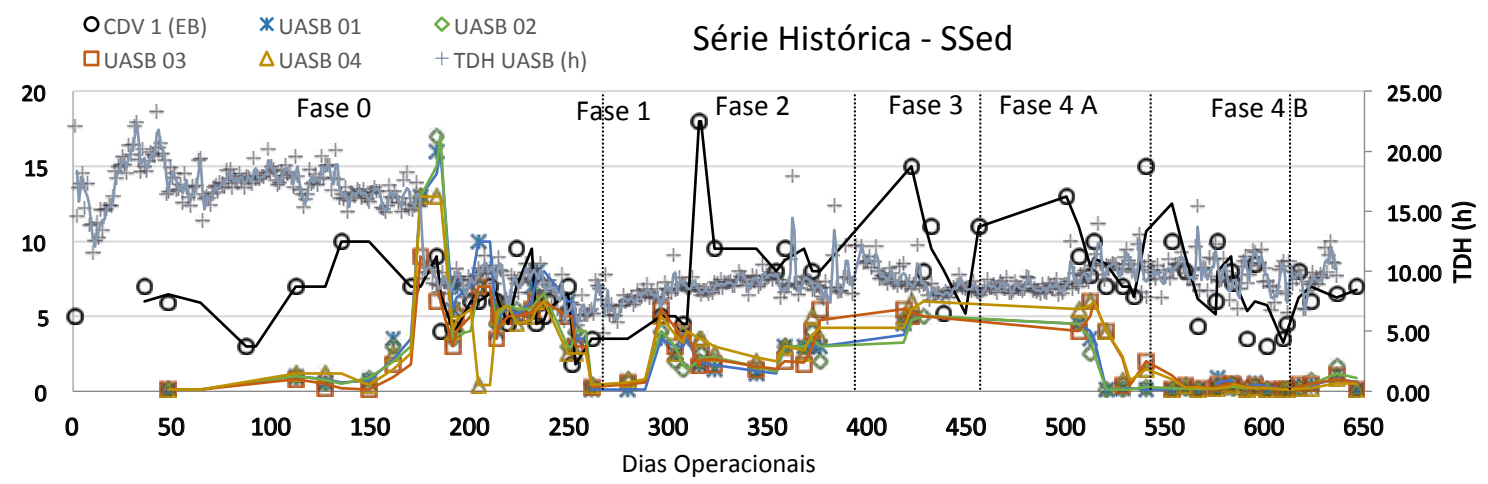

Boxplot - SSed - Análise Global dos UASB

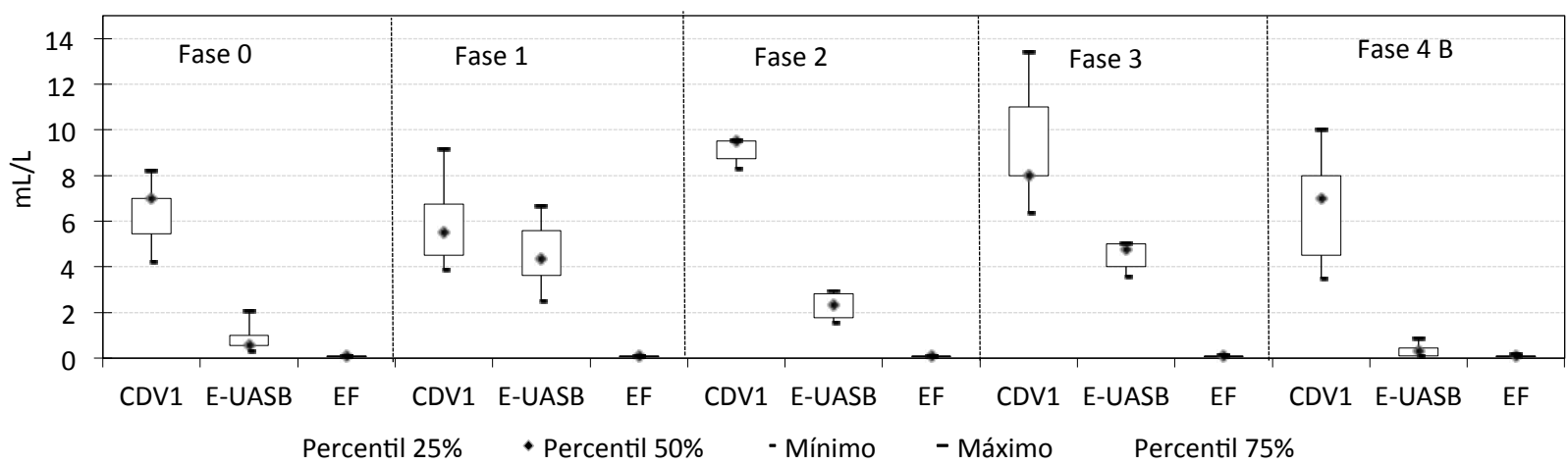

Figura 5 - a) Série Histórica (Afluente e Efluentes dos Reatores) e b) Boxplot análise Global para SSed (Afluente e Efluente da Estação)

\section{Fase 2}

- Durante essa fase de estudo, a carga orgânica volumétrica média afluente aos reatores foi de 1,8 $\mathrm{kgDQO} \cdot \mathrm{m}^{-3} \cdot \mathrm{d}^{-1}$, mesma da fase anterior. Entretanto, com base nas eficiências apresentadas, nota-se que os valores de estabilização de matéria orgânica foram satisfatórios, com remoção de DQO média de $64 \%$ (245 mg. $\left.\mathrm{L}^{-1}\right)$ vista a concentração de entrada de $690 \mathrm{mg} \cdot \mathrm{L}^{-1}$.

- Nota-se também aumento na eficiência de remoção de sólidos, quando comparada à fase 1 , apresentando valores médios de $62 \%$ para SST; e 77\% para SSed (Figura 4 e 5).

- Os valores encontrados, próximos aos valores usuais de eficiência de reatores sem descarte de lodo de excesso, foram obtidos, possivelmente, pelo fato da paralisação do reator (antes do des- carte) permitir o descarte de lodo que se encontrava acima do separador trifásico e do registro superior de descarte (altura de 1,75 m).

- A paralisação dos reatores demonstrou-se inviável, dado o processo manual de suspensão e abaixamento das comportas da caixa distribuidora de vazão, podendo tal procedimento interferir na correta equalização da vazão afluente aos reatores, como pode ser observado nas Figuras 1 e 2 a variação diária em torno do TDH médio.

\section{Fase 3}

- Nessa fase da pesquisa, cabe destacar que houve redução da carga orgânica afluente nos reatores UASB de aproximadamente $8 \%$, o que equivale à afluência de 1,6 kgDQO. $\mathrm{m}^{-3} \cdot \mathrm{d}^{-1}$, demonstrando que a redução na perda de sólidos 
alcançadas na fase anterior contribuiu para o decréscimo no passivo de lodo nos decantadores secundários.

- Entretanto, devido a problemas operacionais como redução e férias de funcionários da ETE, quebra de placas do filtro prensa, falta de cloreto férrico e sobrecarga dos leitos de secagem, nota-se (Figuras 3, 4 e 5 b) que houve queda de eficiência dos reatores UASB, quando comparada à fase 2, com remoção média de $40 \%$ para DQQO, $50 \%$ para SST e eficiência máxima de $45 \%$ para sólidos sedimentáveis.

\section{Fase 4. A}

- Devido aos problemas operacionais anteriormente citados, fez-se necessária a interrupção das análises para adequação dos reatores UASB às necessidades da pesquisa. Para tanto, no período que envolveu o mês de agosto/2014 e a primeira semana de setembro/2014 foi retirado todo o passivo de lodo dos UASB, que se encontrava a altura de $2,0 \mathrm{~m}$, por meio do aumento do número de prensagens no filtro prensa e aumento do volume de lodo descartado. Cabe ressaltar que o passivo de lodo acumulado no decantador secundário também foi retirado por meio da recirculação contínua (24 horas) por 15 dias.

\section{Fase 4. B}

- Nota-se que a carga orgânica afluente aos reatores foi de 2,2 $\mathrm{kgDQO} . \mathrm{m}^{-3} \cdot \mathrm{d}^{-1}$, o que permite inferir que mesmo com carga orgânica superior, a retirada do passivo de lodo do decantador contribuiu para a melhoria da eficiência do tratamento.

- Conforme os resultados apresentados nas Figura 3 a 5, é notória a melhora dos efluentes dos reatores UASB referente à concentração dos parâmetros DQOO, SST e SSed, possivelmente devido à retirada do passivo de lodo dos reatores e do decantador.
- Nota-se que nessa fase a eficiência média de remoção de DQO foi de 75 \%, valor superior ao apresentado na fase 2. De acordo com a Figura $3 \mathrm{~b}$, nessa fase, houve também menor variação nos dados de concentração efluente dos reatores, corroborando a notória melhora do desempenho do UASB.

- A análise da Figura 4b demonstra que a eficiência média de remoção de SST foi de $85 \%$, a maior observada entre as fases de estudo com TDH de 9 horas. $O$ valor apresentado de eficiência de SST sugere que a causa de perda de eficiência nos reatores estava nas altas concentrações de sólidos encontrados no ponto de coleta de $2,0 \mathrm{~m}$, o que ocasionou perda excessiva no efluente dos UASB e consequente deteriorização da caracterização geral (DQO, SST e SSed) do efluente.

- Nota-se na Figura 5b que a fase 4 B apresentou melhor eficiência de remoção de SSed ( 95\%) quando comparada às demais fases, resultando em valor de eficiência de remoção superior àquele observado na Fase 0 (TDH de 18 horas).

- Em termos gerais, cabe ressaltar que a fase 4 apresentou eficiências de remoção compatíveis com os valores usualmente encontrados em ETEs que operam sem descarte de lodo de excesso, permitindo assim inferir que o descarte de lodo de excesso não ocasionou impactos negativos aos reatores UASB durante a fase $4 \mathrm{~B}$.

\subsection{Dinâmica do Lodo nos Reatores UASB}

A Figura 6 apresenta a evolução global dos perfis de sólidos totais (ST) nos reatores UASB utilizados na pesquisa durante as cinco fases operacionais (da fase 0 à fase 4). Cada gráfico representa para cada ponto de amostragem de lodo $(0,5,1,0$, 1,5 e 2,0 m) as médias das concentrações obtidas para os 4 reatores nas diferentes fases. A análise da Figura 6 permite os seguintes comentários: 
- A dinâmica de sólidos dos reatores ao longo das 4 primeiras fases (fases 0 a 3) apresentou concentrações semelhantes, com o lodo bastante concentrado na parte inferior do reator (ponto de amostragem $0,50 \mathrm{~m}$ ) e um pouco menos concentrado nas demais alturas de amostragem $(1,0$; 1,5 e $2,0 \mathrm{~m}$ ).

- No ponto amostral de 0,50 m, as concentrações de ST estiveram sempre entre 4,0 e 4,5\%, que são típicas de reatores UASB tratando esgoto doméstico. Nos pontos amostrais superiores $(1,0$ a 2,0 m), o lodo apresentou concentrações de ST inferiores às observadas no fundo do reator, conforme esperado, variando entre 2,0\% e 3,0\%. Todavia, esperava-se que as concentrações fossem mais baixas, da ordem $0,5 \%$, nos pontos de amostragem mais elevados do compartimento de digestão, de modo a caracterizar a transição do leito de lodo (concentrações acima de 1,5\%) para a manta de lodo (concentrações abaixo de 1,0\%).

- Apenas na fase operacional 4 foi possível observar um perfil de sólidos diferente das demais fases, o que certamente foi devido à melhor estratégia de descarte de lodo praticada durante essa fase. Com o incremento dos descartes de lodo praticados durante a fase $4 \mathrm{~A}$, foi possível remover o excesso de lodo que havia nos reatores da pesquisa, o que resultou na redução significativa das concentrações de sólidos nos pontos mais elevados do compartimento de digestão, cerca de $1,7 \%$ no ponto amostral $1,50 \mathrm{~m}$ e abaixo de $0,5 \%$ no ponto amostral $2,0 \mathrm{~m}$.
- Observa-se que a evolução das concentrações de ST no ponto de amostragem a 2,0 m esteve relacionada com as eficiências médias de remoção de DQQ e SST anteriormente citadas. A manutenção de baixas concentrações de lodo na parte superior do compartimento de digestão torna-se essencial para que se possa evitar o acúmulo de lodo no interior do compartimento de decantação, condição importante para reduzir a perda de sólidos e a deterioração da qualidade do efluente do reator.

- Analisando conjuntamente os perfis de sólidos mostrados na Figura $6 \mathrm{com}$ as concentrações efluentes de DQO, SST e SSed mostradas nas Figuras 3 a 5, é possível observar que as fases $0 \mathrm{e}$ 4 foram as únicas em que se obteve baixas concentrações desses parâmetros no efluente dos reatores da pesquisa. Infere-se que as baixas concentrações de DQO, SST e SSed estiveram relacionadas às menores perdas de sólidos no efluente durante essas duas fases, as quais, por sua vez, foram decorrentes de: i) maior TDH (18 h) e menor velocidade ascensional $(\mathrm{v}=0,24 \mathrm{~m} / \mathrm{h})$ durante a fase 0; e ii) menor concentração de lodo na parte mais elevada do compartimento de digestão (< $0,5 \%$ no ponto de amostragem $2,0 \mathrm{~m}$ ) na fase 4 .

- De modo geral, a manutenção de biomassa com concentração de 4 a 4,5 \% na altura de 0,5 m, mesmo com a ausência de descarte de lodo a essa altura, pode ser importante para o descarte de lodo de excesso por amortecer as variações de carga orgânica e conferir maior resistência a choques hidráulicos na biomassa, possibilitando, assim, a manutenção da biomassa com maior atividade biológica. 


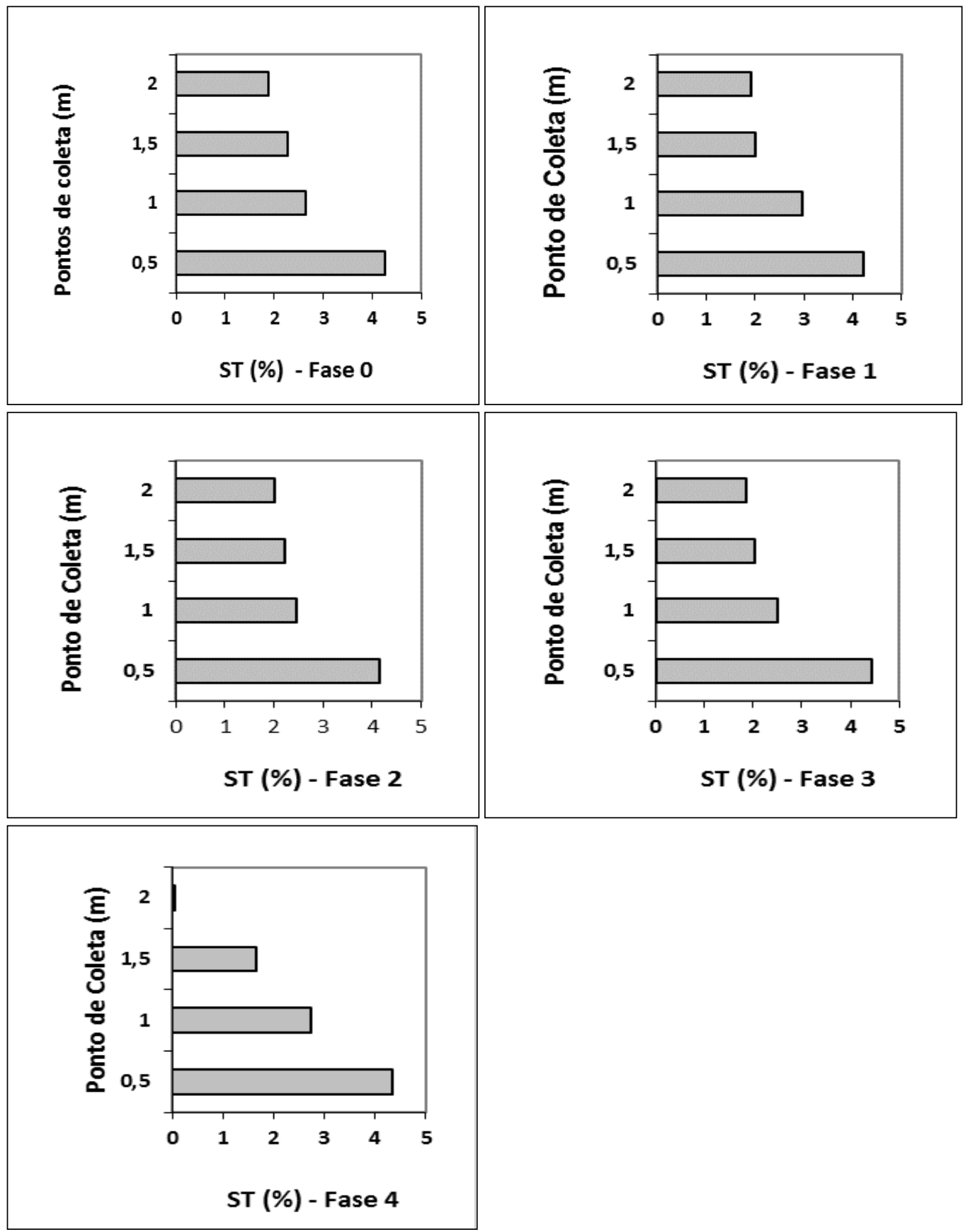

Figura 6 - Dinâmica de sólidos nos reatores UASB para as 5 fases da pesquisa 


\subsection{Análise Global da Estação}

Abaixo, apresenta-se um análise global da ETE comparando as concentrações afluentes e efluentes da estação:

- Apesar da baixa eficiência encontrada em algumas fases da pesquisa, a estação apresentou desempenho global médio de remoção de DQO para as fases $0,1,2$, 3 e 4 de 87, 88, 88, 88 e $89 \%$, respectivamente.

- No que se refere à concentração de SST no efluente final, a estação apresentou eficiência global durante as fases de estudo de 95, 90, 94, 94 e $94 \%$.

- Em relação à concentração de sólidos sedimentáveis no efluente final da estação, os valores encontrados foram sempre abaixo de $0,1 \mathrm{~mL} / \mathrm{L}$.

- A análise das Figuras 3, 4 e 5 B permite inferir que o descarte de lodo de excesso não é prejudicial ao desempenho global da ETE, que quando bem operada pode apresentar eficiência de remoção relevante e produzir efluente com qualidade superior ao estabelecido pelos padrões de lançamento e aumento da produção de biogás.

\section{CONCLUSÕES}

A operação dos reatores com TDH de 9 horas mostrou-se dependente da manutenção e controle da massa de lodo no interior dos reatores anaeróbios. Os resultados encontrados no decorrer da pesquisa demonstraram que o descarte de excesso de lodo para adensamento e digestão em reatores UASB não é o causador de perda de sólidos e degradação da qualidade do efluente de reatores UASB. Os problemas até então notados, no que diz respeito aos elevados valores de SST observados nos efluentes dos reatores e à perda de eficiência de remoção de matéria orgânica, estão ligados diretamente ao gerenciamento ineficiente do lodo de excesso nos reatores UASB. Ademais, outros problemas operacionais vivenciados numa ETE, como: i) baixa capacidade de desidratação devido ao dimensionamento ineficiente dos sistemas; ii) dificuldades encontradas para o descarte diário de lodo dos reatores; iii) falta de produtos químicos complementares à desidratação; iv) dimensionamento ineficiente dos tanques de lodo, dentre outros, podem agravar ainda mais a situação de perda de sólidos, o que resulta em queda de eficiência dos reatores.

Baseado nos resultados obtidos pela pesquisa, conclui-se que a perda excessiva de sólidos no efluente dos reatores pode ser evitada com o estabelecimento de um adequado gerenciamento para o descarte de lodo de excesso secundário e a manutenção nos reatores UASB de concentração de lodo na parte superior do compartimento de digestão (antes do defletor de gases) inferior a 1,0\%. Preferencialmente, a concentração de sólidos nesse ponto não deve ultrapassar a $0,5 \%$.

\section{REFERÊNCIAS}

AISSE, M. M. et al. Avaliação do sistema reator UASB e filtro biológico aerado submerso para o tratamento de esgoto sanitário. In: CONGRESSO BRASILEIRO DE ENGENHARIA SANITÁRIA, 23.,2001, Campo Grande. Anais...João Pessoa: ABES, 2001.

APHA-AWWA-WPCF. Standard methods for the examination of water and wastewater. 19a ed. Washington, D.C.: Ed. APHA, 1995, $1587 \mathrm{p}$.

BOF, V. S; CASTRO, M. S.M.; GONÇALVES, R. F. ETE UASB + Biofiltro aerado submerso: desempenho operacional com retorno do lodo aeróbio para o UASB. In: CONGRESSO BRASILEIRO DE ENGENHARIA SANITÁRIA, 20, 1999, Rio de Janeiro. Anais...Rio de Janeiro: ABES, 1999.

CASEIRO, A. H.; PIVELLI, R. P.; SOBRINHO, P. A. Reator UASB Tratando Esgoto Sanitário e Digerindo Lodo Aeróbio Excedente. In: CONGRESSO INTERAMERICANO DE INGENIERÍA SANITARIA Y AMBIENTAL, 30. 2006, Punta del Este. Anais...Punta del Este: AIDIS, 2006.

CHERNICHARO, C. A. L. et al. Secondary sludge return for thickening and digestion in UASB reactors: case study of Onça STP - Brazil. In: SIMPOSIO LATINO AMERICANO DE DIGESTIÓN ANAEROBIA XI. 2014, LA HABANA, CUBA. Anais... LA HABANA, CUBA, 2014. 
COSENTINO, P. R. S. et al. Estabilização de lodo de sistemas aeróbios em reatores do tipo UASB. In: CONGRESSO BRASILEIRO DEENGENHARIA SANITÁRIA, 23, 2005, Campo Grande. Anais...Rio de Janeiro: ABES, 2005

COURA, M. A.; VAN HAANDEL, A.C. Viabilidade técnica e econômica do digestor anaeróbio de fluxo ascendente (UASB) no sistema anaeróbio/aeróbio. In: CONGRESSO BRASILEIRO DEENGENHARIA SANITÁRIA, 20, 1999, Rio de Janeiro. Anais...Rio de Janeiro: ABES, 1999.

FREIRE, V. H.; VON SPERLING, M; CHERNICHARO, C. A. L. Avaliação do desempenho de um sistema combinado UASB - Lodo ativado no tratamento de efluentes sanitários. In: CONGRESSO BRASILEIRO DEENGENHARIA SANITÁRIA, 20, 1999, Rio de Janeiro. Anais.. Rio de Janeiro: ABES, 1999.

GONÇALVES, R.F. et al. Using a UASB reactor for thickening and digestion of discharged sludge from submerged aerated biofilters. Water Science and Technology, v. 45, n.10, p. 299-304, 1999.

JENÍCEK, P. J.; DOHÁNYOS, M.; ZÁBRANSKÁ, J. Combined anaerobic treatment of wastewater and sludges. Water Science and Technology, v. 40, n.1, p. 85-91, 1999.

KASSAB, G. et al. Sequential anaerobic-aerobic treatment for domestic wastewater - A review. Bioresource Technology, v.101, n.10, p.3299-3310, 2010.

METCALF, E.; EDDY, M. Wastewater engineering: treatment, disposal and reuse. 3rd edição. New York: McGraw-Hill Inc., 1991, $1334 \mathrm{p}$.

MAGALHÃES, K. M. Avaliação do retorno do lodo aeróbio sobre a eficiência dos reatores UASB da estação de tratamento de esgoto de Itabira. 2012. 49 f. Monografia (Especialização em Engenharia Sanitária e Ambiental) - Escola de Engenharia da Universidade Federal de Minas Gerais, Belo Horizonte, 2012.

ORTEGA, C. L.; ROBLES, A N.; BOHÓRQQUEZ, S. S. Efecto de lodos ativados de purga sobre el funcionamento de un reator UASB pilo- to y las caracteristicas del lecho de lodo granular. In: CONGRESSO PANAMERICANO DE INGIENIERIA SANITARIA E AMBIENTAL, 25, 1996, México. Anais... México: AIDIS, 1996.

PONTES, P. P. Reatores UASB aplicados ao tratamento combinado de esgotos sanitários e lodo excedente de filtro biológico percolador. 2003. 214 f. Tese (Doutorado em Saneamento, Meio Ambiente e Recursos Hídricos) - Escola de Engenharia da Universidade Federal de Minas Gerais, Belo Horizonte, 2003.

PONTES, P. P.; CHERNICHARO, C. A. L. Efeito do retorno de lodo aeróbio sobre as características da biomassa presente em reatores UASB tratando esgoto sanitário. Engenharia Sanitária e Ambiental, v. 14, n.2, p. 223-234, 2009.

SILVA FILHO, J. A.; VAN HAANDEL, A. C. Estabilização de Lodo de Pós-Tratamento Aeróbio na Unidade de Pré-tratamento Anaeróbio. DAE, n. 194, p. 86 - 102.

SOUSA, J. T. Pós-tratamento de efluente de reator anaeróbio de fluxo ascendente em reator aeróbio sequencial em batelada e coluna de lodo anaeróbio para desnitrificação. 1996. 258 f. Tese (Doutorado em Engenharia Civil) - Escola de Engenharia de São Carlos, Universidade de São Paulo, São Carlos.

VAN HAANDEL, A.C.; LETTINGA, G. Tratamento anaeróbio de esgotos: um manual para países de clima quente. Campina Grande: EPGRAF, 1994.

VERONEZ, F. A.; GONÇALVES, R. F. Produção de biogás em um reator tratando esgoto sanitário e lodo de descarte de biofiltros aerados submersos. In: SIMPÓSIO ÍTALO BRASILEIRO DE ENGENHARIA SANITÁRIA E AMBIENTAL, 6., 2001, Espirito Santo. Anais... Espirito Santo: SIBESA, 2001.

WANKE, R. et al. Utilização de Estações de Tratamento de Esgotos modulares compactas associando reatores anaeróbios e aeróbios na região sudeste do Brasil. In: TALLER Y SIMPOSIO LATINOAMERICANO SOBRE DIGESTIÓN ANAEROBIA, 7., 2002, Mérida, Yucatán, México. Anais...Mérida: IWA, 2002. p. 229-232. 